\title{
ChemComm
}

\section{Lanthanide cation-templated synthesis of rotaxanes $\uparrow$}

\author{
Cite this: Chem. Commun., 2013, \\ 49, 8157 \\ Received 17th July 2013, \\ Accepted 1st August 2013
}

DOI: $10.1039 / \mathrm{c3cc45404e}$

www.rsc.org/chemcomm

The first lanthanide cation-templated synthesis of an interlocked structure is demonstrated through an interpenetrated assembly between a pyridine $\mathrm{N}$-oxide threading component coordinating to a lanthanide cation complexed within a macrocycle. Stoppering of the pseudo-rotaxane assembly allows for preparation of the [2]rotaxane.

The development of new innovative strategic templating routes for the construction of mechanically interlocked molecules with potential molecular switching and machine-like nanotechnological applications is of intense current research interest. ${ }^{1}$ In addition to their dynamic behaviour, rotaxanes and catenanes can also be designed to contain topologically unique threedimensional cavities for molecular recognition and sensing applications. ${ }^{2}$ Although transition metal cation, and to a lesser extent alkali and alkaline earth metal cation, templates have been imaginatively exploited in the synthesis of rotaxanes and catenanes, ${ }^{3}$ to the best of our knowledge, the utilization of lanthanides as potential templating reagents for interlocked molecular framework assembly has not been demonstrated. ${ }^{4}$ This is somewhat surprising given the usefulness of luminescent lanthanide complexes in imaging and assay. ${ }^{5}$ We describe herein the first lanthanide-cation templated synthesis of a rotaxane.

Adapting our recently reported sodium and barium cation templated synthesis of a rotaxane using the pyridine $\mathrm{N}$-oxide motif, ${ }^{6}$ the synthetic strategy undertaken for the preparation of the target lanthanide-[2]rotaxane is shown in scheme 1. A kinetically stable lanthanide complexed DOTA cyclen derivative integrated into a macrocyclic structural framework, forms initially a pseudo-rotaxane assembly with an appropriately functionalised pyridine $\mathrm{N}$-oxide threading component, where the pyridine $N$-oxide ligand serves to satisfy the lanthanide cation's coordination sphere. Subsequent stoppering of the

Chemistry Research Laboratory, Department of Chemistry, University of Oxford, Mansfield Road, Oxford, OX1 3TA, UK. E-mail: paul.beer@chem.ox.ac.uk; Fax: +44 (0)1865 272690

$\dagger$ Electronic supplementary information (ESI) available: Experimental details for synthetic and spectroscopic procedures, and additional characterisation. See DOI: $10.1039 / \mathrm{c} 3 \mathrm{cc} 45404 \mathrm{e}$

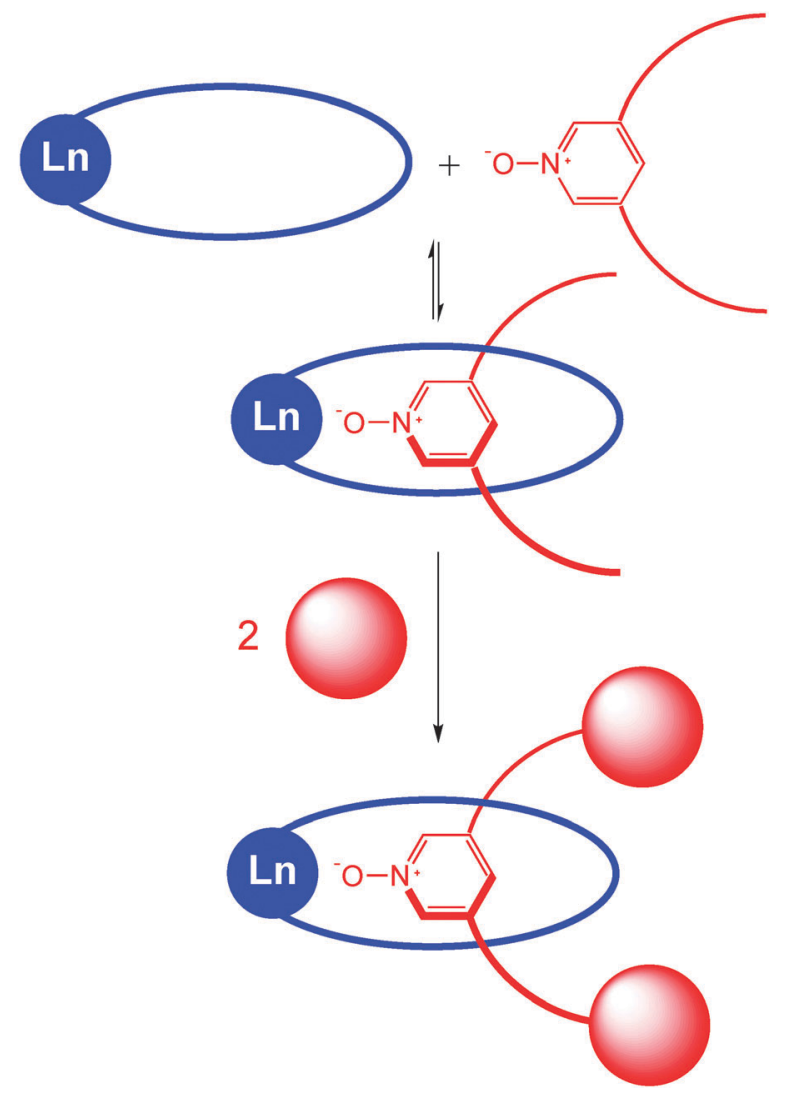

Scheme 1 Schematic representation for the preparation of the target lanthanide-[2]rotaxane.

interpenetrated assembly produces the novel lanthanide containing interlocked structure.

The synthetic procedure used for preparation of the lanthanide macrocyclic component $\mathbf{4 a}$ and $\mathbf{4 b}$ of the target [2]rotaxane system and the bis-azide functionalised pyridine $\mathrm{N}$-oxide thread component is outlined in Scheme 2.

Two of the nitrogen atoms of cyclen were selectively alkylated with tert-butyl bromoacetate to give bis-ester cyclen 1, using established procedures. ${ }^{7}$ The bridging unit 2 was prepared by 
a)<smiles>CCCCNCCNCCN(CC(=O)OCC(C)(C)C)CC(=O)OCC(C)(C)C</smiles><smiles></smiles>

.

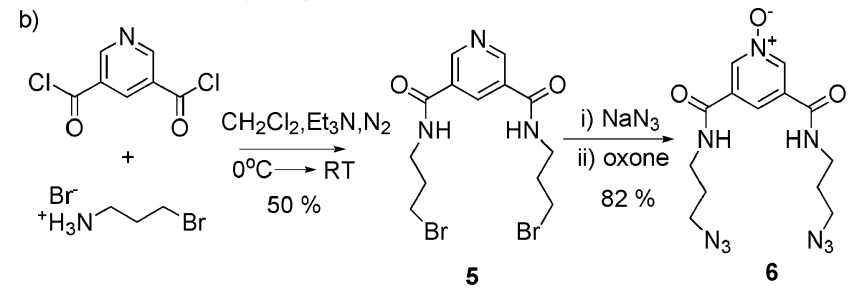

Scheme 2 Synthesis of (a) lanthanide macrocyclic complexes and (b) bis-azide pyridine $\mathrm{N}$-oxide thread component.

condensing two equivalents of chloroacetyl chloride with the corresponding bis-amine derivative ${ }^{8}$ (see ESI $\dagger$ ). Reaction of the 1,7-DO2A diester 1 and the bis-amide compound 2 in acetonitrile under basic conditions afforded macrocycle 3, which was isolated in $70 \%$ yield after purification by recrystallization from diethyl ether. Cleavage of the tert-butyl ester groups in $\mathbf{3}$ followed by complexation of the resulting product with either lutetium or europium trifluoromethanesulfonate salts in methanol, produced the lanthanide complexes $\mathbf{4 a}$ and $\mathbf{4 b}$ in a quantitative yield. The condensation reaction between 3,5-bis-chlorocarbonyl pyridine and two equivalents of 3-bromopropylamine hydrobromide in dry $\mathrm{CH}_{2} \mathrm{Cl}_{2}$ in the presence of triethylamine gave the bis-bromo amide pyridine derivative 5 in $50 \%$ yield. Azide nucleophilic substitution followed by oxidation using oxone afforded the bis-azide pyridine $N$-oxide compound 6 in $80 \%$ yield.

The synthesis of the target lanthanide [2] rotaxanes was achieved by a copper(I) catalysed cycloaddition azide-alkyne (CuAAC) click stoppering reaction as shown in Scheme 3. A solution of the appropriate lanthanide macrocyclic complex (4a and $\mathbf{4 b}$ ), bis-azide pyridine $N$-oxide axle precursor 6 and two equivalents of alkynefunctionalised terphenyl stopper 7 in dichloromethane in the presence of a catalytic amount of $\mathrm{Cu}\left(\mathrm{CH}_{3} \mathrm{CN}\right)_{4} \mathrm{PF}_{6}$ was stirred at room temperature for 48 hours. After purification using size exclusion chromatography, the rotaxanes $\mathbf{8 a}$ and $\mathbf{8 b}$ were isolated
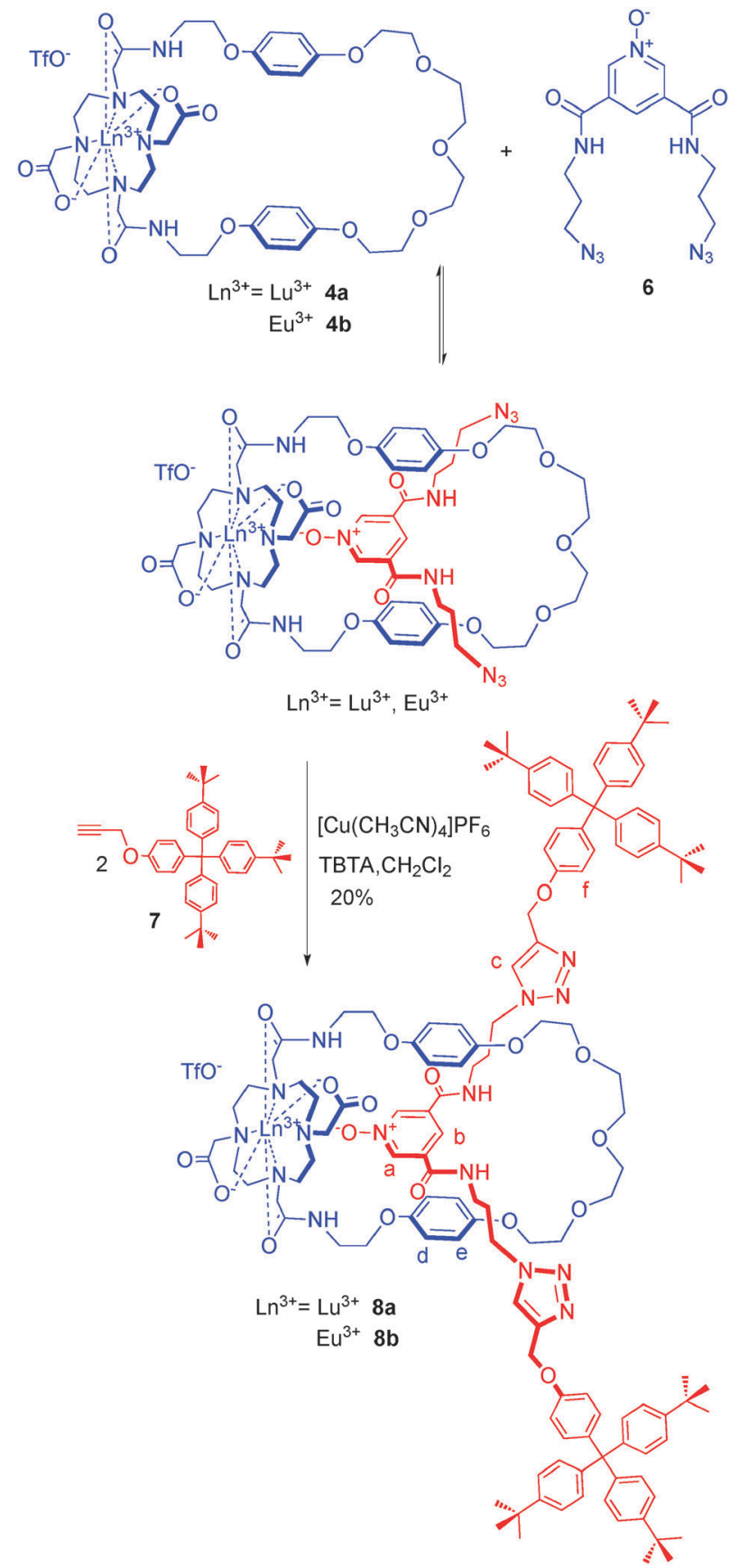

Scheme 3 Synthesis of lanthanide [2]rotaxanes $8 \mathbf{a}$ and $8 \mathbf{b}$. TBTA $=($ tris $-[(1-$ benzyl-1H-1,2,3-triazol-4-yl)methyl]amine).

in $20 \%$ yield, and were characterized by high-resolution electrospray mass spectrometry (Fig. 1) and ${ }^{1} \mathrm{H}$ NMR. ${ }^{9}$

A comparison of the ${ }^{1} \mathrm{H}$ NMR spectra of the [2] rotaxane 8a, macrocycle 4a and stoppered axle is shown in Fig. 2. The upfield shifts of the macrocycle hydroquinone protons observed with $\mathbf{8 a}$ are diagnostic of aromatic donor-acceptor stacking interactions between the electron rich hydroquinone groups of the macrocycle and the electron deficient pyridine $\mathrm{N}$-oxide axle motif. Two-dimensional ${ }^{1} \mathrm{H}-{ }^{1} \mathrm{H}$-ROESY spectroscopy was also used to confirm the interlocked nature of rotaxane 8a with throughspace correlations between protons in the respective axle and 


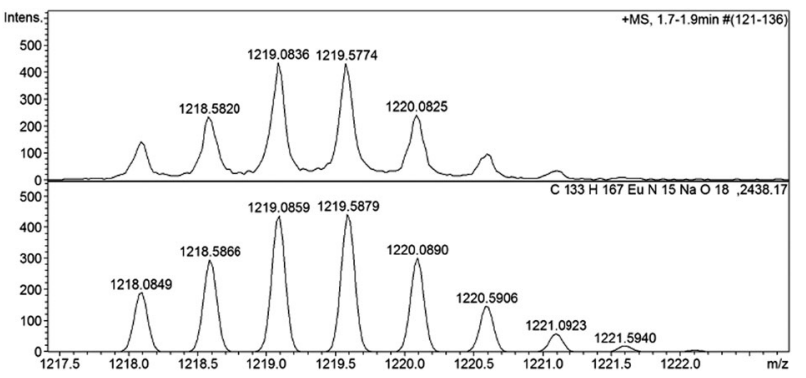

Fig. 1 High resolution electrospray ionization mass spectrum of [2]rotaxane $8 \mathrm{~b}$ (top) with theoretical isotope model for $[\mathrm{M}-\mathrm{TfO}+\mathrm{Na}]^{2+}$ (bottom).

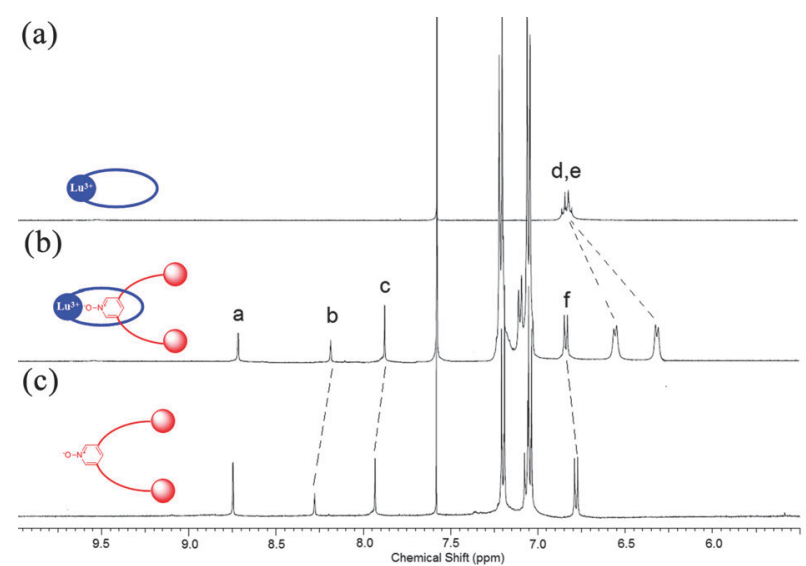

Fig. 2 Partial ${ }^{1} \mathrm{H}$ NMR spectra in $\mathrm{CDCl}_{3}-\mathrm{CD}_{3} \mathrm{OD} 1: 1$ at $293 \mathrm{~K}$ of (a) macrocycle 4a, (b) [2]rotaxane 8a, and (c) axle. For atom labels see Scheme 3.

macrocycle components being identified (see Fig. SI8, ESI + ). ${ }^{10}$ An equimolar solution of cyclen macrocycle 3 and pyridine $\mathrm{N}$-oxide derivative 6 in $\mathrm{CD}_{2} \mathrm{Cl}_{2}$ revealed no upfield perturbations of the macrocycle's hydroquinone protons which suggests the contribution of aromatic donor-acceptor interactions to the overall mechanical bond formation process is minimal and highlights the crucial templating role of the lanthanide cation. ${ }^{11}$

The luminescence from the europium centre was also used to probe the structure of macrocycle $4 \mathbf{b}$ and rotaxane $8 \mathbf{b}$ in $1: 1$ $\mathrm{CH}_{2} \mathrm{Cl}_{2}: \mathrm{CH}_{3} \mathrm{OH}$ and in $1: 1 \mathrm{CD}_{2} \mathrm{Cl}_{2}: \mathrm{CD}_{3} \mathrm{OD}$. In the former solvent mixture, the observed luminescence lifetime of $\mathbf{8 b}$ was found to be $0.94 \mathrm{~ms}$, while in deuterated media the luminescence lifetime increased to $1.18 \mathrm{~ms}$. Understanding solvation of even simple systems in binary solvent mixtures is not straightforward, but given the residual charge on the lanthanide centre, it is reasonable to assume that any inner sphere solvent at the europium ion will be comprised of methanol rather than $\mathrm{CH}_{2} \mathrm{Cl}_{2}$ molecules. As such it is possible to estimate $q$, the number of inner sphere solvent molecules bound to the lanthanide, from the equation $q=2.4\left(\tau_{\mathrm{CH}_{3} \mathrm{OH}}{ }^{-1}-\tau_{\mathrm{CD}_{3} \mathrm{OD}}{ }^{-1}-0.125-0.0375 x\right)$, where $x$ is the number of exchangeable amide $\mathrm{N}-\mathrm{H}$ oscillators close to the metal centre. ${ }^{12}$ In this case, the calculated value of $q$ is 0 if we assume that all four amide $\mathrm{N}-\mathrm{H}$ oscillators contribute (including the two on the axle), which certainly equates to exclusion of methanol from the inner coordination sphere in $\mathbf{8 b}$, and suggests that the pyridine $N$-oxide oxygen atom acts as an axial donor to the lanthanide. The luminescence lifetime of 4b in $1: 1 \mathrm{CH}_{2} \mathrm{Cl}_{2}: \mathrm{CH}_{3} \mathrm{OH}$ is shorter and a biexponential fit gives 0.20 and $0.63 \mathrm{~ms}$, indicating solvation at the europium centre in contrast to $\mathbf{8 b}$.

In summary, the first lanthanide cation-templated synthesis of an interlocked structure has been demonstrated. A pyridine $N$-oxide ligand threading component coordinates to a lutetium or europium lanthanide complexed DOTA cyclen motif which is itself incorporated into a macrocycle. The novel lanthanide [2]rotaxanes are prepared through stoppering of the pseudorotaxane assemblies.

F.Z. acknowledges the Ministry of Education of Spain for a Postdoctoral contract (Programa Nacional de Movilidad de Recursos Humanos del Plan Nacional I+D+I 2008-2011). O.A.B. thanks the European Research Council for funding under the European Union's Framework Program (FP7/20072013) ERC Advanced Grant Agreement no. 267426. M.J.L. thanks the EPSRC for a DTA studentship.

\section{Notes and references}

1 (a) E. R. Kay and D. A. Leigh, Pure Appl. Chem., 2008, 80, 17; (b) J. A. Faiz, V. Heitz and J.-P. Sauvage, Chem. Soc. Rev., 2009, 38, 422; (c) L. Fang, M. A. Olson, D. Benítez, E. Tkatchouk, W. A. Goddard III and J. F. Stoddart, Chem. Soc. Rev., 2010, 39, 17; (d) M. D. Lankshear and P. D. Beer, Acc. Chem. Res., 2007, 40, 657; (e) M. S. Vickers and P. D. Beer, Chem. Soc. Rev., 2007, 36, 211; (f) S. J. Loeb, Chem. Soc. Rev., 2007, 36, 226-235.

2 (a) G. T. Spence and P. D. Beer, Acc. Chem. Res., 2013, 46(2), 571-586; (b) M. J. Chmielewski, J. J. Davis and P. D. Beer, Org. Biomol. Chem., 2009, 7, 415-424.

3 (a) J. P. Sauvage, Acc. Chem. Res., 1990, 23, 319; (b) J. C. Chambron, J. P. Collin, V. Heitz, D. Jouvenot, J. M. Kern, P. Mobian, D. Pomeranc and J. P. Sauvage, Eur. J. Org. Chem., 2004, 1627; (c) J. F. Stoddart, Templates in Chemistry II, Springer, Berlin/Heidelberg, 2005, pp. 227-240; (d) J. E. Beves, B. A. Blight, C. J. Campbell, D. A. Leigh and R. T. McBurney, Angew. Chem., Int. Ed., 2011, 50, 9260-9327; (e) J. D. Crowley, S. M. Goldup, A.-L. Lee, D. A. Leigh and R. T. McBurney, Chem. Soc. Rev., 2009, 38, 1530-1541.

4 We have recently reported lanthanide appended rotaxanes, prepared by post-rotaxane formation. See C. Allain, P. D. Beer, S. Faulkner, M. W. Jones, A. M. Kenwright, N. L. Kilah, R. C. Knighton, T. J. Sorensen and M. Tropiano, Chem. Sci., 2013, 4, 489-493. Hoffart and Loeb have used pyridine $N$-oxide at the terminus of rotaxanes for the construction of MOFs. See D. J. Hoffart and S. J. Loeb, Angew. Chem., Int. Ed., 2005, 44, 901-904.

5 (a) S. Faulkner, L. S. Natrajan, W. S. Perry and D. Sykes, Dalton Trans., 2009, 3890-3899; (b) C. Allain and S. Faulkner, Future Med. Chem., 2010, 2, 339-350.

6 L. M. Hancock and P. D. Beer, Chem. Commun., 2011, 47, 6012-6014.

7 (a) L. M. De León-Rodríguez, Z. Kovacs, A. C. Esqueda-Oliva and A. D. Miranda-Olvera, Tetrahedron Lett., 2006, 47, 6937-6940; (b) T. Hirayama, M. Taki, A. Kodan, H. Kato and Y. Yamamoto, Chem. Commun., 2009, 3196-3198.

8 L. M. Hancock and P. D. Beer, Chem.-Eur. J., 2009, 15, 42-44.

9 The by-products from the reaction were non-interlocked macrocycle and axle.

10 Addition of 1 equivalent of axle to macrocycle $4 a$, in $1: 1 \mathrm{CD}_{2} \mathrm{Cl}_{2}$ $\mathrm{CD}_{3} \mathrm{OD}$, revealed no perturbation of the hydroquinone protons in the ${ }^{1} \mathrm{H}$ NMR spectrum. This further confirms that the upfield shifted hydroquinones observed in rotaxane $8 \mathbf{a}$ are due to the interlocked nature of the axle and macrocycle components, and demonstrates that the stopper components prevent the macrocycle threading-dethreading. This rules out the possibility of the axle perching on the outside of the macrocycle, and confirms that the rotaxane is mechanically interlocked (see ESI $\dagger$ ).

11 The copper(I) catalysed (CuAAC) stoppering rotaxane synthesis reaction cannot be undertaken in the absence of the lanthanide cation template because of the propensity of the DOTA ligand to complex copper.

12 (a) A. Beeby, I. M. Clarkson, R. S. Dickens, S. Faulkner, D. Parker, L. Royle, A. S. de Sousa, J. A. G. Williams and M. Woods, J. Chem. Soc., Perkin Trans. 2, 1999, 493; (b) S. Faulkner, S. J. A. Pope and B. P. Burton-Pye, Appl. Spectrosc. Rev., 2005, 40, 1-31. 